\title{
Frontières
}

\section{Merci Madame Faucher}

\section{Diane Laflamme}

Volume 16, numéro 1, automne 2003

Remède ou poison?

URI : https://id.erudit.org/iderudit/1073752ar

DOI : https://doi.org/10.7202/1073752ar

Aller au sommaire du numéro

Éditeur(s)

Université du Québec à Montréal

ISSN

1180-3479 (imprimé)

1916-0976 (numérique)

Découvrir la revue

Citer ce document

Diane (2003). Merci Madame Faucher. Frontières, 16(1), 3-4.

https://doi.org/10.7202/1073752ar

Ce document est protégé par la loi sur le droit d'auteur. L'utilisation des services d'Érudit (y compris la reproduction) est assujettie à sa politique d'utilisation que vous pouvez consulter en ligne.

https://apropos.erudit.org/fr/usagers/politique-dutilisation/
Cet article est diffusé et préservé par Érudit.

Érudit est un consortium interuniversitaire sans but lucratif composé de l’Université de Montréal, l'Université Laval et l'Université du Québec à Montréal. Il a pour mission la promotion et la valorisation de la recherche. https://www.erudit.org/fr/ 


\section{$\mathrm{MERCl}$ \\ MADAME FAUCHER}

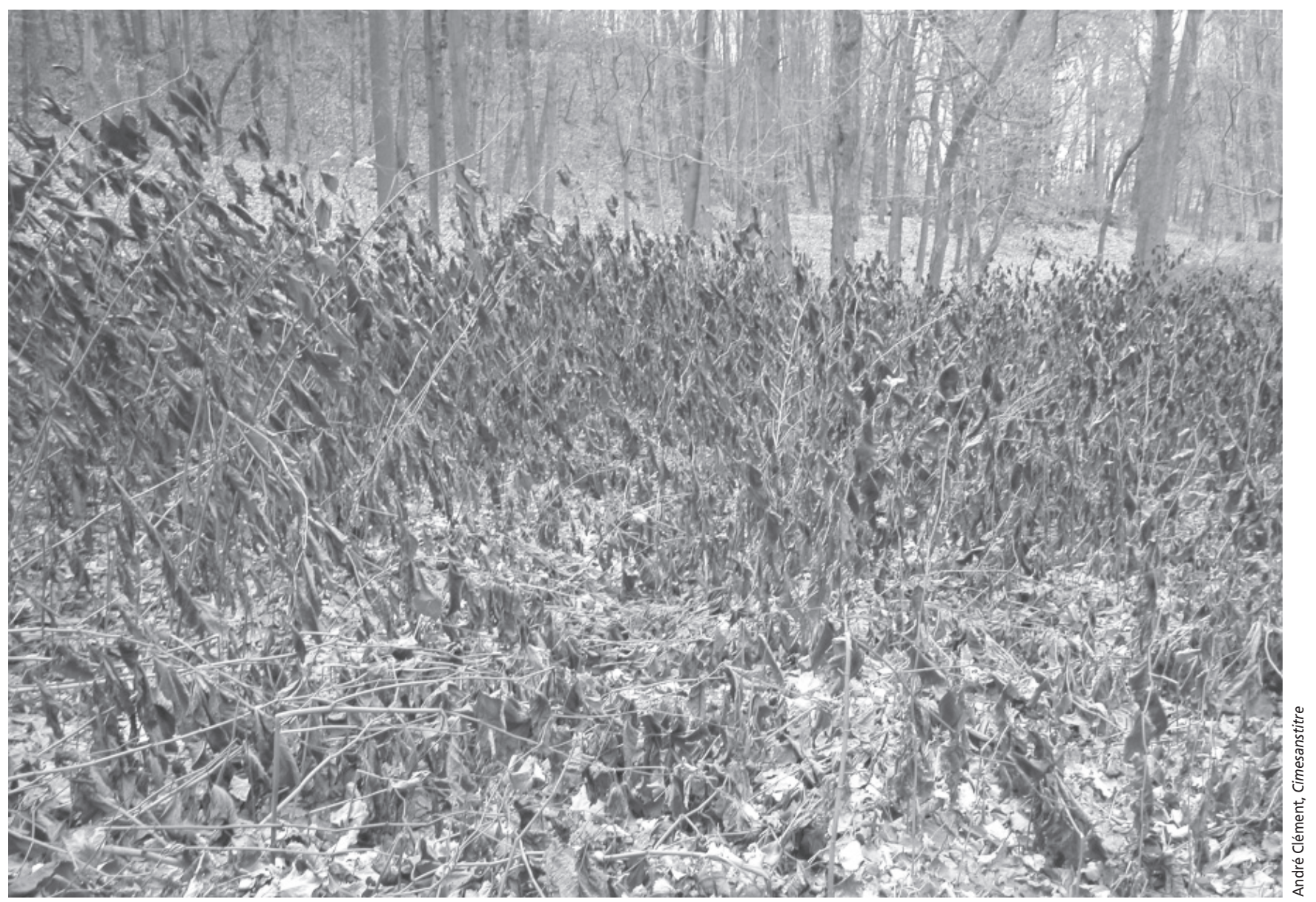

Diane Laflamme, Ph.D.,

rédactrice en chef.

Fin 1970, la jeune diplômée enthousiaste et fraîchement arrivée à Montréal que j'étais alors se retrouva avec de douloureux ennuis de santé. Un cas plutôt banal pour les médecins de la métropole, qui eurent tôt fait de diagnostiquer un calcul rénal. On me recommanda d'attendre avant d'envisager une chirurgie. J'étais bien d'accord, mais je me retrouvais néanmoins à la merci d'une douleur d'une intensité indescriptible, qui pouvait se manifester n'importe quand sans prévenir. L'injection d'un calmant réussissait alors à me rendre momentanément absente à la douleur, mais le prix à payer au réveil prenait la forme de violents vomissements.

Mes parents habitaient encore à l'époque le petit village des Appalaches où je suis née. Ma mère s'est souvenue d'un ancien remède : la racine de savoyane ${ }^{1}$. Elle s'est adressée à madame Faucher, une dame âgée qui habitait dans l'un des rangs du village, pour lui demander d'en récolter pour moi. Madame Faucher savait effectivement où trouver cette plante et comment la préparer. Quelques jours plus tard, elle a apporté à ma mère les minuscules rhizomes. À Montréal, j'en ai fait une infusion. Je me souviens encore jusqu'à quel point c'était amer!

Mes ennuis de santé se sont assez vite réglés. Je ne saurai jamais la part exacte qu'a joué la savoyane dans toute cette histoire. Je sais par ailleurs que madame Faucher, qui ne connaissait de moi que mon visage d'enfant, l'a cueillie avec bienveillance pour aider l'adulte au parcours urbain inconnu que j'étais progressivement devenue. Ce qui me chagrine, en racontant cette histoire, c'est de constater que je ne suis jamais retournée dans le rang qu'habitait madame Faucher pour la remercier.

Je sais qu'elle a demandé de mes nouvelles; je sais que ma mère l'a remerciée pour moi. J'ai souvent entendu ma mère rendre hommage à ces femmes ${ }^{2}$ du village qui l'ont aidée : madame Côté, qui a su intervenir auprès de ma sœur, 
encore bébé, qui souffrait de méningite; madame Pouliot, qui venait chez nous lorsque ma mère accouchait ; madame Chabot, qui...

À mon tour, je veux rendre hommage ici à ces femmes capables de soigner! Madame Faucher repose maintenant dans le petit cimetière de notre village. Je voudrais tant savoir si, avant de partir, elle a enseigné à quelqu'un comment récolter la savoyane.

\section{DÉCOUVERTES GÉNIALES ET RÉACTIONS BARBARES}

Madame Faucher et le village de mon enfance appartenaient à un Québec bien différent de celui qui est le nôtre aujourd'hui. Les générations qui ont remplacé celle de madame Faucher ont vite cessé de se promener dans les champs à la recherche de plantes médicinales pour s'installer confortablement au volant de l'énorme machine du progrès. $\mathrm{Ne}$ comptez pas sur moi pour me plaindre de toutes ces découvertes géniales dont nous bénéficions aujourd'hui, du téléphone cellulaire à la navigation sur Internet, en passant par les lecteurs DVD et... notre carte d'assurance-maladie. Je me contenterai de déplorer que nos réactions barbares à l'univers ultrasophistiqué qui nous sollicite aujourd'hui nous rendent plus souvent qu'autrement incapables de prendre soin : prendre soin de notre propre santé, prendre soin de nos parents qui vieillissent et qui vont mourir, prendre soin des jeunes qui essaient de bâtir un premier projet bien à eux, prendre soin des institutions démocratiques qui nous ont été confiées, prendre soin de l'environnement dont nous avons hérité. Incapables; nous cherchons plus souvent qu'autrement à refiler la responsabilité à quelqu'un d'autre.

J'ai écrit réactions barbares; vous avez probablement pensé «invasions barbares» après avoir vu tant de fois l'expression sur de grandes affiches et l'avoir entendue dans tous les médias au cours des derniers mois. C'est à un psychiatre, Hubert Wallot, et à un journaliste, Jean-Pierre Bonhomme, que je laisse le soin de commenter ces invasions sur grand écran. Je me réjouis qu'un événement cinématographique d'une telle envergure nous invite à parler plus ouvertement du prendre soin qui précède le moment de la mort. C'est dans un Québec que nous sommes capables de reconnaître que Denis Arcand a campé les personnages de son film. Deux générations sont en présence. La plus jeune reçoit le mandat de prendre soin de l'autre, et elle y réussit à grands coups d'argent, de débrouillardise par satellite, de mots d'amour prononcés près d'un lac et... de bien autre chose que de la racine de savoyane.

Du cinéma, glissons vers les photographies d'André Clément qui habitent ce numéro. L'univers de l'artiste se déploie en parallèle pour accompagner la thématique abordée par nos auteurs dans des articles qui questionnent, chacun à leur façon, ce que nous nommons parfois remède, parfois poison. La prochaine fois que je chercherai de la savoyane, ou d'autres savoirs pour mieux prendre soin, j'irai me pronener dans la forêt d'André Clément; vous l'avez vue à la page précédente et vous la retrouverez aux pages 72 et 73 . C'est tout près de chez nous!

\section{Notes}

1. Lamoureux, Gisèle (dir.) (1975). Les plantes sauvages printanières, Québec, Éditeur officiel du Québec, ministère des Communications : Coptis groenlandica "On extrait une teinture jaune du rhizome et le nom populaire, savoyane, vient d'un mot amérindien signifiant teinture pour les peaux», p. 57. Voir aussi Index des plantes curatives, p. 233 à 235.

2. Les noms cités ici ne sont pas des pseudonymes. 